\title{
Our Experience of Using Thermally Recycled Silica Gel in a Teaching and Small Research Laboratory Setting ${ }^{\dagger}$
}

\author{
Fatima Sbait Wahshi ${ }^{1}$, Maitha Dhaiman Alqahtani ${ }^{1}$, Manhal Abdulla ${ }^{1}$, Abdullah Al-Hemyari ${ }^{1}$, \\ Muna Bufaroosha ${ }^{1}$, Tholkappiyan Ramachandran ${ }^{2}$, Fathalla Hamed ${ }^{2}$ and Thies Thiemann 1,* \\ 1 Department of Chemistry, United Arab Emirates University, P.O. Box 15551, Al Ain, UAE; \\ 200423643@uaeu.ac.ae (F.S.W.); 201305267@uaeu.ac.ae (M.D.A.); 201350100@uaeu.ac.ae (M.A.); \\ 200935268@uaeu.ac.ae (A.A.-H.); muna.bufaroosha@uaeu.ac.ae (M.B.) \\ 2 Department of Physics, United Arab Emirates University, P.O. Box 15551, Al Ain, UAE; \\ t_ramachandran@uaeu.ac.ae (T.R.); fhamed@uaeu.ac.ae (F.H.) \\ * Correspondence: thies@uaeu.ac.ae; Tel.: +971-3-713-6121 \\ + Presented at the 22nd International Electronic Conference on Synthetic Organic Chemistry, 15 November- \\ 15 December 2018; Available Online: https://sciforum.net/conference/ecsoc-22.
}

Published: 14 November 2018

\begin{abstract}
Organic synthetic research laboratories generate a large amount of waste. Some of the waste is the silica gel used as the stationary phase in column chromatographic separations. Here, the authors discuss the possibility of recycling silica gel wastes thermally at $600{ }^{\circ} \mathrm{C}$, at which temperature the remnant adsorbed organic material combusts. It could be shown that the recycled silica gel maintains its adsorption characteristics. The process could be repeated 10 times with any discernable deterioration of the separation properties of the silica gel for the product mixture of the reactions used in this research. In those cases where triphenyl oxide remained on the silica gel after the separation of the reaction mixture, such as after Wittig olefination and Appel-type reactions, an increase of phosphorus content was noted in the silica gel after thermal treatment. The original and recycled silica gel was partly analyzed by Brunauer-Emmett-Teller (BET) surface measurements, scanning electron microscopy (SEM), energy-dispersive X-ray spectroscopy (EDS) and in inductively coupled plasma optical emission spectroscopy (ICP-OES). The process significantly reduced waste production in our laboratory and also led to a reduction in costs associated with acquiring new silica gel and with the management and the disposal of spent silica gel. A simple environmental impact assessment has been carried out.
\end{abstract}

Keywords: silica gel; chemical waste; column chromatography; thermolysis; environmental impact assessment

\section{Introduction}

In organic synthetic chemistry, silica gel is used extensively as the stationary phase in column chromatographic separations of reaction mixtures. Oftentimes, the used silica gel is declared as waste and not re-used. When chemicals remain adsorbed on the silica gel, it needs to be treated as hazardous chemical waste in most countries. Both the waste disposal of spent silica gel and the acquisition of new silica gel is costly, looking at the financial as well as the environmental aspect. There has been an ongoing discussion [1-4] on the usefulness of recycling silica gel as stationary phase material, where oftentimes the recycling suggested consists of eluting and thereby removing adsorbed substances with polar solvents such as with ethyl acetate and methanol, followed by water and drying the silica gel in an oven at $800^{\circ} \mathrm{C}$ [1] or oxidative treatment, e.g., with an aqueous solution 
of $\mathrm{KMnO}_{4}$ and $\mathrm{H}_{2} \mathrm{SO}_{4}$, with subsequent washings with oxalic acid and deionized water, followed by heat treatment at $120{ }^{\circ} \mathrm{C}$ [1] or with a treatment of an aqueous solution of $\mathrm{H}_{2} \mathrm{O}_{2}$ and subsequently deionized water, followed by heat treatment at $120^{\circ} \mathrm{C}$ [1] or by $\mathrm{H}_{2} \mathrm{O}_{2}-$ solar light [2]. It has been noted that silica gel will lose adsorbed water at its surface already below $150^{\circ} \mathrm{C}$ and that silanol groups will convert to siloxanes at above $300{ }^{\circ} \mathrm{C}$ [5-7] and that this may lead to structural instability [4] and thus to lower separation properties of the heat-treated silica. In addition, it has been warned against using such recycled silica gel for the work-up of untested reactions in research. Nevertheless, in view of the costs incurred by discarding used silica gel as wastes, the recycling of silica gel in educational and small research laboratories may have to re-addressed. Here, we have studied the possibility of recycling silica gel by simple heating to $600{ }^{\circ} \mathrm{C}$ in an oven, thereby combusting the organic residues that remain adsorbed to the silica gel at the end of the column chromatographic separation. The current work also looks at the use of multiple recycled silica gels.

\section{Experimental}

\subsection{General}

Silica gel of Merck grade 9385 (fine, pore size $60 \AA$, 230-400 mesh, bp. $2230{ }^{\circ} \mathrm{C}, \mathrm{mp} .>1600{ }^{\circ} \mathrm{C}$ ) was used in the experiments. The thermal treatment of the silica gel during the recycling process was carried out in a Carbolite electrical oven ELF 11-6. For the sieving process of the silica gel after the combustion process, Retsch $180 \mu \mathrm{m}$ and $425 \mu \mathrm{m}$ sieves were used. Brunauer-Emmett-Teller (BET) surface area and porosity studies were carried out on a Micromeritics TriStar II Plus 2.03 instrument. P-content was measured by ICP-OES with a Varian 720-ES spectrometer. For the organic products separated on the recycled silica gel, melting points were measured on a Stuart SMP 10 melting point apparatus and are uncorrected. Infrared spectra were measured with a Thermo/Nicolet Nexus 470 FT-IR ESP Spectrometer. ${ }^{1} \mathrm{H}$ and ${ }^{13} \mathrm{C}$ NMR spectra were recorded with a Varian $400 \mathrm{NMR}$ spectrometer $\left({ }^{1} \mathrm{H}\right.$ at $395.7 \mathrm{MHz},{ }^{13} \mathrm{C}$ at $\left.100.5 \mathrm{MHz}\right)$. The assignments of the carbon signals were aided by DEPT 90 and DEPT 135 experiments (DEPT = Distortionless Enhancement by Polarization Transfer). The chemical shifts are relative to TMS (solvent $\mathrm{CDCl}_{3}$, unless otherwise noted). Mass spectra were measured with a JMS-01-SG-2 spectrometer and with an Agilent QTOF 6540 UHD.

\subsection{Thermal Recycling of the Silica Gel}

Typically, after the column chromatography of a reaction mixture over silica gel Merck grade 9385, the solvent loaded silica gel was versed onto a glass fritte and air dried with suction, where remaining solvent was collected in a vacuum flask. The dried silica gel was entered into a crucible and pre-heated in a Carbolite electrical oven at $300{ }^{\circ} \mathrm{C}$ for $30 \mathrm{~min}$.; thereafter, it was heated at $600{ }^{\circ} \mathrm{C}$ for $2 \mathrm{~h}$, which includes a time interval of approximately $35 \mathrm{~min}$. to reach the temperature plateau at $600{ }^{\circ} \mathrm{C}$ (see heating response curve, Figure 1). After $2 \mathrm{~h}$, the oven is set back to room temperature, where it takes approximately $35 \mathrm{~min}$. to reach $300^{\circ} \mathrm{C}$ (see the cooling curve, Figure 2). After cooling to room temperature, the silica gel is sieved through a $180 \mu \mathrm{m}$ steel mesh. Experiments have also been carried out at lower $\left(500^{\circ} \mathrm{C}\right.$ and $\left.550^{\circ} \mathrm{C}\right)$ temperature and higher temperatures $\left(700^{\circ} \mathrm{C}\right)$. Temperatures lower than $600{ }^{\circ} \mathrm{C}$ did not lead to complete combustion of the carbonaceous material. On the other hand, thermal gravimetric analyses (TGAs) of most of our carbon-containing materials have shown that at $600{ }^{\circ} \mathrm{C}$ samples combusted completely. Therefore, in order to avoid structural changes to the silica gel and to contain energy use, the authors opted for thermolysis at $600{ }^{\circ} \mathrm{C}$ instead of at $800{ }^{\circ} \mathrm{C}$, a temperature that is often used for the complete ashing of carbon-containing materials.

The sieved silica gel is stored in a container and reused only after 3-4 weeks of resting in order to ensure rehydration of the surface of the silica gel. The particles that remain in the sieve and contain sea-sand, if used as a protective layer during the column chromatography, or salts, if the organic reaction mixture has not been extracted with water prior to the chromatography, are collected, sieved through a $425 \mu \mathrm{m}$ steel mesh, washed with water and dried. The material that remains in the sieve is sea-sand (if used) that is pure enough to re-use in subsequent column chromatography. 


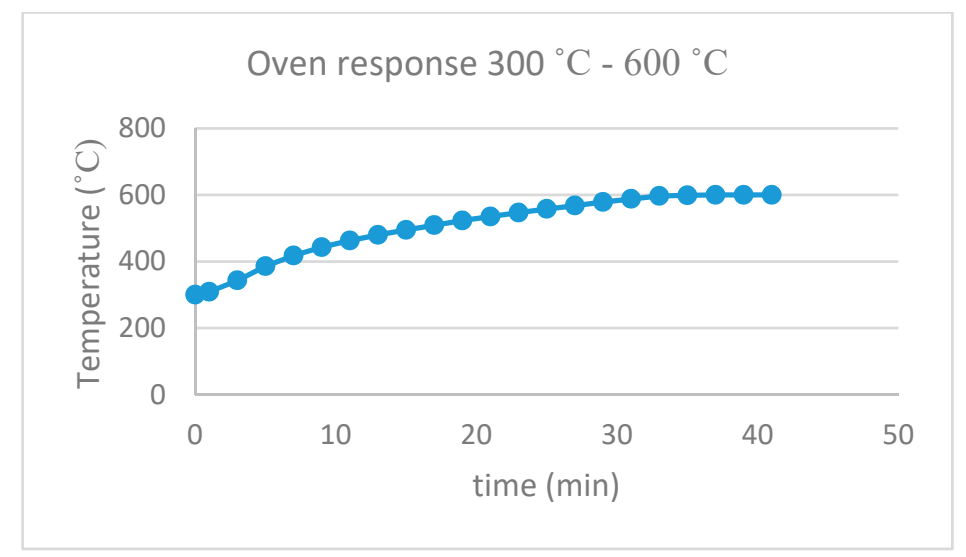

Figure 1. Heating curve of the Carbolite electrical oven $\left(300^{\circ} \mathrm{C}-600{ }^{\circ} \mathrm{C}\right)$ with $100 \mathrm{~g}$ silica gel sample.

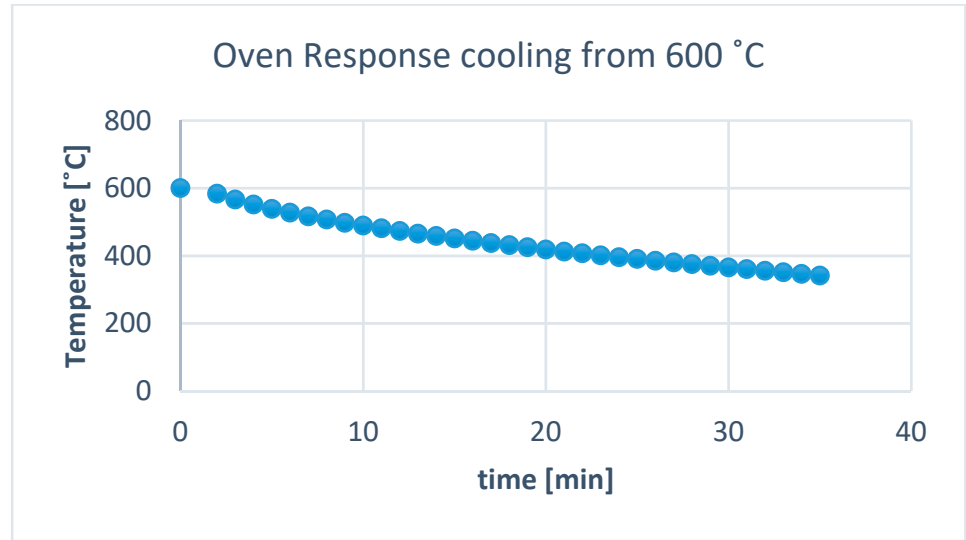

Figure 2. Cooling curve of the Carbolite electrical oven $\left(600^{\circ} \mathrm{C}-300^{\circ} \mathrm{C}\right)$ with $100 \mathrm{~g}$ silica gel sample.

\subsection{Preparation of Isopropyl 4-Hydroxybenzoate (16) Using Recycled Silica Gel in the Purification Step}

To triphenylphosphine $\left(\mathrm{PPh}_{3}, 3.78 \mathrm{~g}, 14.4 \mathrm{mmol}\right)$ in $\mathrm{CH}_{2} \mathrm{Cl}_{2}(20 \mathrm{~mL})$ was added dropwise bromotrichloromethane $\left(\mathrm{BrCCl}_{3}, 3.12 \mathrm{~g}\right.$, $\left.15.7 \mathrm{mmol}\right)$, and the resulting solution was stirred for $35 \mathrm{~min}$. at room temperature, during which time it turned dark-yellow. To the solution was added 4hydroxybenzoic acid (14) $(1.71 \mathrm{~g}, 12.4 \mathrm{mmol})$, and the mixture was stirred at reflux for $10 \mathrm{~h}$. Thereafter, the cooled reaction mixture was concentrated and subjected directly to column chromatography on $5 \mathrm{X}$ recycled silica gel $\left(\mathrm{CH}_{2} \mathrm{Cl}_{2}\right)$. Thereafter, the fraction comprising the product was extracted with $5 \mathrm{w} \%$ aqueous $\mathrm{NaHCO}_{3}(50 \mathrm{~mL})$. The organic phase was dried and concentrated in vacuo to give $16\left(1.81 \mathrm{~g}, 81 \%\right.$ ) as a slowly crystallizing colorless (white) solid, mp. $85^{\circ} \mathrm{C}$ (Lit. $88^{\circ} \mathrm{C}$ [8]); IR $\left(\mathrm{KBr} / \mathrm{cm}^{-1}\right) \vee 3400,1685,1610,1590 ;{ }^{1} \mathrm{H} \mathrm{NMR}\left(400 \mathrm{MHz}, \mathrm{CDCl}_{3}\right) 1.36\left(6 \mathrm{H}, \mathrm{d},{ }^{3} \mathrm{~J}=6.0 \mathrm{~Hz}\right), 5.23$ $\left(1 \mathrm{H}\right.$, sept., $\left.{ }^{3} \mathrm{~J}=6.0 \mathrm{~Hz}\right), 6.89\left(2 \mathrm{H}, \mathrm{d},{ }^{3} \mathrm{~J}=7.6 \mathrm{~Hz}\right), 6.98(1 \mathrm{H}, \mathrm{bs}, \mathrm{OH}), 7.95\left(2 \mathrm{H}, \mathrm{d},{ }^{3} J=7.6 \mathrm{~Hz}\right) ;{ }^{13} \mathrm{C}$ NMR $\left(100.5 \mathrm{MHz}, \mathrm{CDCl}_{3}\right) 21.2\left(2 \mathrm{CH}_{3}\right), 68.6(\mathrm{CH}), 115.2(2 \mathrm{C}, \mathrm{CH}), 122.7$ (C $\left.\mathrm{C}_{\text {quat }}\right), 131.9(2 \mathrm{C}, \mathrm{CH}), 160.4$ ( $\left.\mathrm{C}_{\text {quat }}\right)$, 166.8 ( $\left.\mathrm{C}_{\text {quat }}, \mathrm{CO}\right)$.

\section{Results and Discussion}

SEM studies (Figure 3) of the original silica gel Merck grade 9385 and for the recycled silica gel (e.g., $5 \mathrm{X}$ recycled) show no noticeable difference in size, in shape or morphology. This is supported by Brunauer-Emmett-Teller (BET) surface measurements with a BET surface area of $394.5 \mathrm{~m}^{2} / \mathrm{g}$ for the original silica gel, $387.8 \mathrm{~m}^{2} / \mathrm{g}$ for $1 \mathrm{X}$ recycled silica gel and $422.3 \mathrm{~m}^{2} / \mathrm{g}$ for $2 \mathrm{X}$ recycled silica gel, showing a slight decrease in BET surface area, but then even a slight increase after the second recycling. The average (adsorption) pore diameter ( $4 \mathrm{~V} / \mathrm{A})$ decreases, however, from $78.5 \AA$ of the original silica gel over $72.7 \AA$ (for 1 x recycled silica gel) to $65.9 \AA$ (for 2 X recycled silica gel). For the original silica gel Merck grade 9385, only Si and O could be found in the EDS measurement. In those instances, where product mixtures were separated which included and left triphenylphosphine oxide 
on the silica gel after separation, phosphorus content was found on the silica gel in both ICP (P content $960 \mathrm{ppm}$ for $10 \mathrm{X}$ recycled silica gel) and EDS (P content $1.04 \mathrm{w} \%$ for $10 \mathrm{X}$ recycled silica gel) measurements. In comparison, the P-content of the commercially bought silica gel Merck grade 9385 was found to be $1.3 \mathrm{ppm}$. Recently, investigations have appeared on the thermolysis behavior of triarylphosphine oxide, especially when used as building blocks in co-polymers. It is generally thought that the triarylphosphine oxide is converted to phosphoric acid upon combustion and after cooling and hydration $[9,10]$, where it is likely that amounts of polyphosphoric acids remain, where in our case phosphoric acids can also be esterified with silanol groups.

(a)

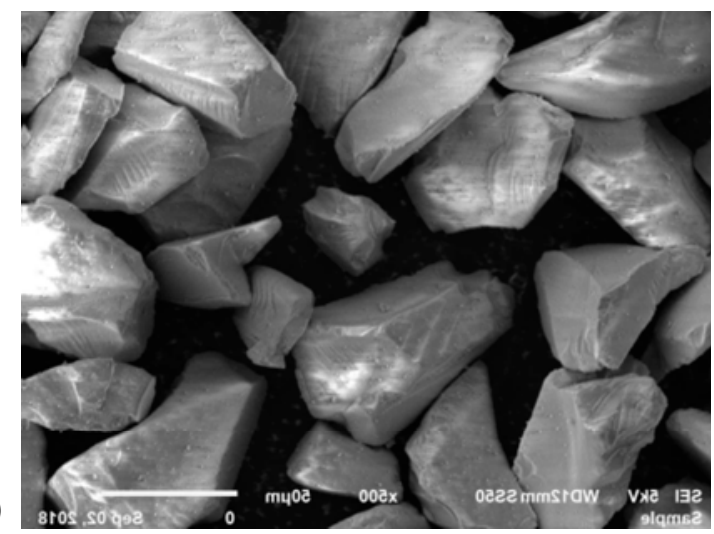

(b)

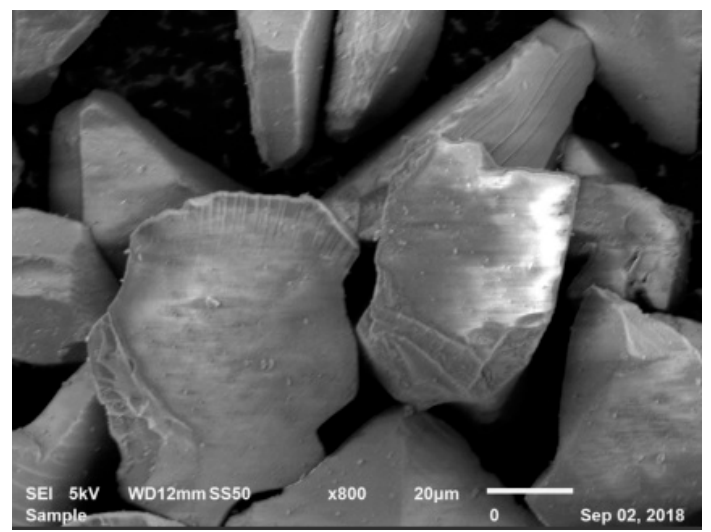

Figure 3. Scanning electron microscopy (SEM) micrograph of commercial silica gel Merck grade 9385 (a, left) and 10X recycled silica gel Merck grade 9385 (b, right).

In those cases where sea-sand was used as a protective covering layer in the column chromatography, both the sodium and sulfur contents in the recycled silica gel rose (to $1.4 \mathrm{w} \% \mathrm{Na}$ and to $775 \mathrm{ppm} S$ for $10 \mathrm{X}$ recycled silica gel).

Clearly, water will be lost when the silica gel is heated. When used as a desiccant, silica gel is recycled at $120{ }^{\circ} \mathrm{C}$. At higher temperatures, it is known that silanols form siloxanes by an ether linkage. Surface siloxane functions in the calcined silica gel are expected to convert back to silanols. This can be expected to happen at room temperature. Using IR- and Raman spectroscopy [11-14], much work has been performed in the literature on the mechanism of the hydroxylation of silica gel surface, where the ring opening of the strained surface siloxanes is thought to be exothermic. We found that after the thermolysis, the recycled silica gel gradually took up water so that by day 8 (at rt) about $7.9 \mathrm{w} \%$, by day 10 (at rt) $9.1 \mathrm{w} \%$ of the mass of the silica gel is water, either bound to the surface of the silica gel, inserted into the silica gel by siloxane cleavage or as interstitial water. By day 13 , the water content reached $10.1 \mathrm{w} \%$, after which it did not change (Figure 4 ). This reflects the result of thermogravimetric measurements of commercially acquired silica gel and 5X recycled silica gel, where weight losses of $11.1 \mathrm{w} \%$ and $8.1 \mathrm{w} \%$, respectively, were noted upon heating the samples to $600^{\circ} \mathrm{C}$.

Typical reactions that have been performed and where the reaction mixtures were separated on recycled silica gel are shown in Figures 5-8. They include two Williamson ether syntheses to methyl 4-ethoxybenzoate (3) (Figure 5) and to the steroidal azobenzene 6 with alkenylazobenzene 7 as side product (Figure 6) and two reactions that generate triphenylphosphine oxide as a by-product, namely a Wittig reaction to cinnamate 10 (Figure 7) and a Appel-type reaction utilizing $\mathrm{BrCCl}_{3}-\mathrm{PPh}_{3}$ as a reagent [15] to azo cinnamate 13 (Figure 8). For these reactions, the reaction products could be separated by column chromatography on recycled silica gel to give products in yield and purity equal to the products gained from chromatographic separations with commercial (i.e., non-recycled) silica gel. 


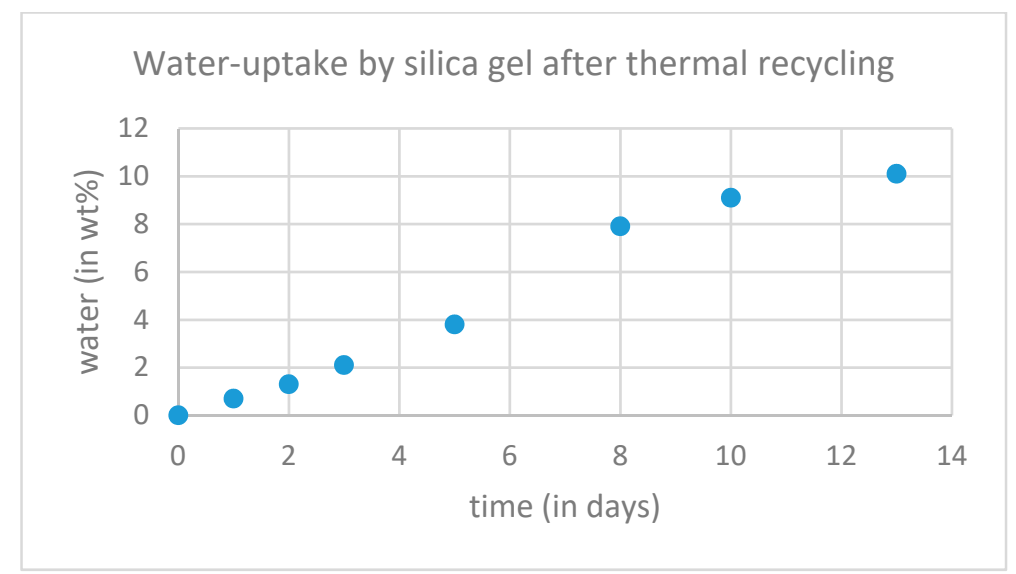

Figure 4. Water-uptake of the silica gel after thermal treatment at $600{ }^{\circ} \mathrm{C}$.

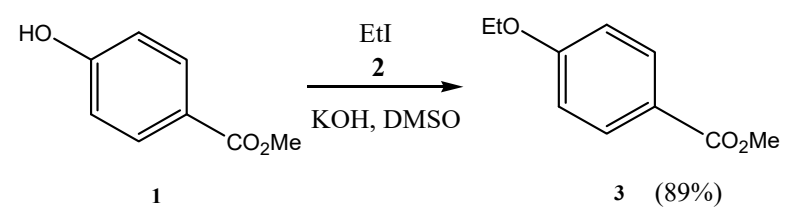

Figure 5. Preparation of methyl 4-ethoxybenzoate (3).

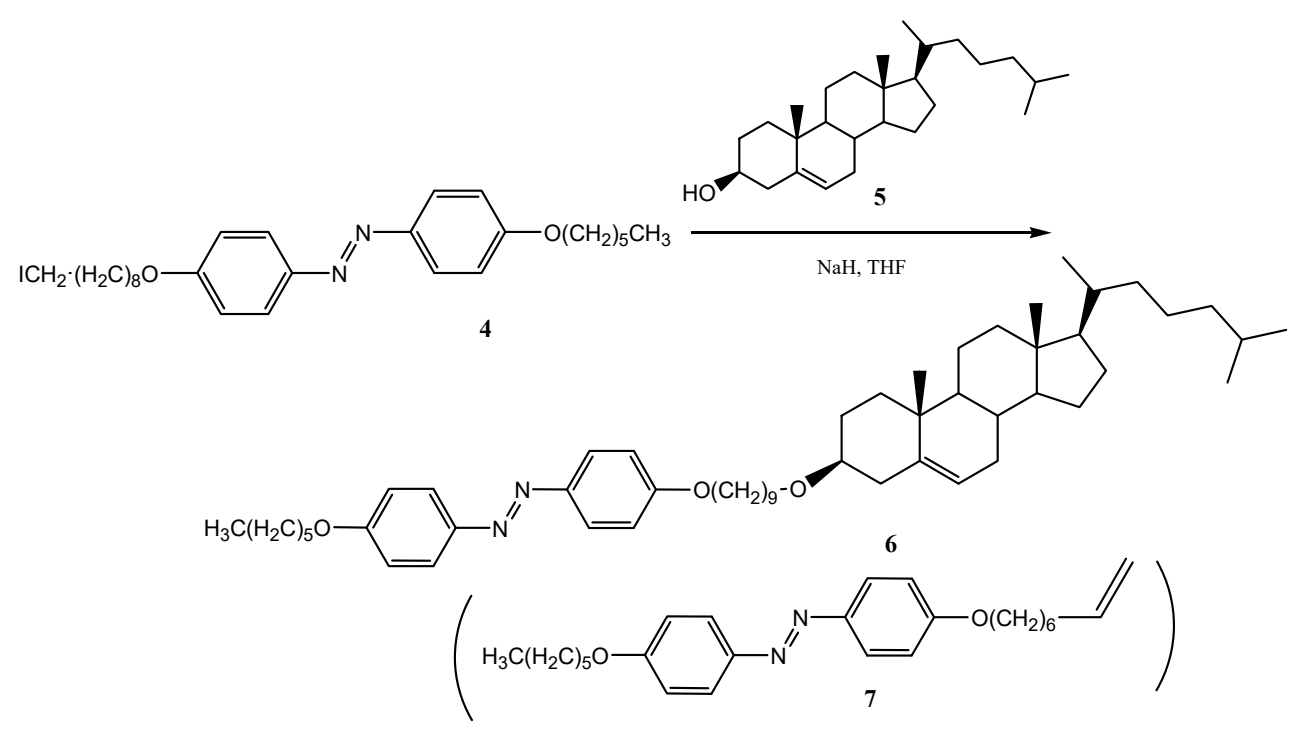

Figure 6. Williamson ether synthesis of steroidal azobenzene 6.

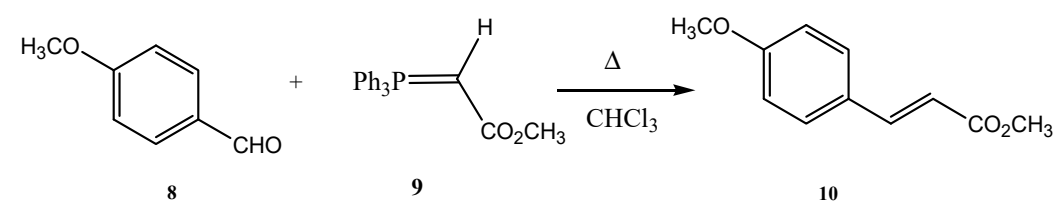

Figure 7. Wittig-olefination to cinnamate $\mathbf{1 0 .}$ 


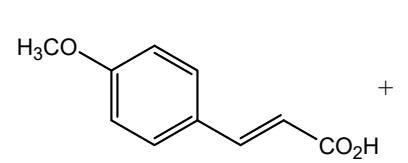

11

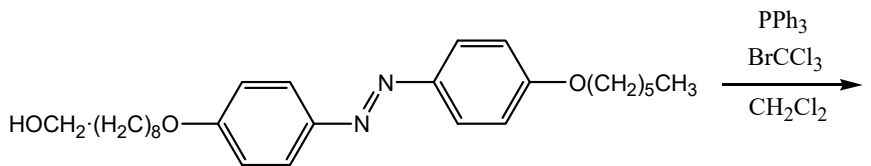

12

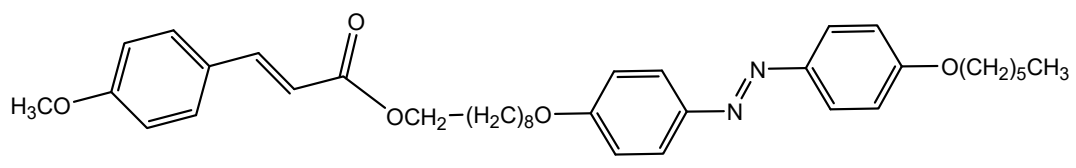

13

Figure 8. Appel-type reaction using $\mathrm{BrCCl}_{3}-\mathrm{PPh}_{3}$ to azo cinnamate 13.

An exception was found to be the purification of isopropyl 4-hydroxybenzoate (16) (Figure 9), prepared by Appel-type esterification from 4-hydroxybenzoic acid (14), using $\mathrm{PPh}_{3} / \mathrm{BrCCl}_{3}$ as a reagent, where the product partially hydrolyzed on the silica gel during the chromatography. While some hydrolysis was found to occur under identical conditions with commercial silica gel, the yield of the product was by $4 \%$ lower using recycled silica gel. The final product could be purified by extraction of the fraction obtained from the column chromatographic separation with an aq. $\mathrm{NaHCO}_{3}$ solution.

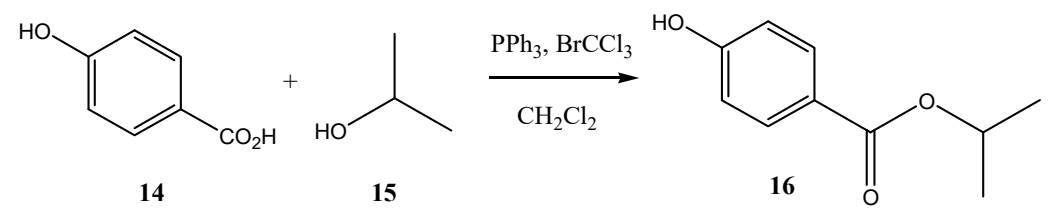

Figure 9. Preparation of 4-hydroxybenzoate (16) by Appel-type esterification using $\mathrm{BrCCl}_{3}-\mathrm{PPh}_{3}$.

\section{Environmental Impact Assessment}

The industrial cycle of manufacturing silica gels consists mainly of five steps [16]. These steps are raw material acquisition, the synthesis, washing (acid/liquid filtration), drying and finally the storage [16]. For the production of silica gel, the raw materials used are alkali metal silicate solutions and acids (usually sulphuric acid $\left[\mathrm{H}_{2} \mathrm{SO}_{4}\right]$ ). The manufacturing starts with the addition of $\mathrm{H}_{2} \mathrm{SO}_{4}$ to an aqueous solution of sodium silicate to form a silica gel. The silica is then washed to increase its concentration and to get rid of by-products like sodium sulfate $\left(\mathrm{Na}_{2} \mathrm{SO}_{4}\right)$. After washing, the silica gel is dried.

For the convenience of study, we can separate these stages into two main stages; the wet stage, and the dry stage. The wet stage represents every step associated with silica gel making, from the use of sodium silicate to washing the silica gel. The dry stage, on the other hand, includes the drying of the filter cake [16] and the packaging and storage of the final product. In the wet stage, a lot of water is used, especially in the washing step to ensure the purity of silica. The wastewater generated from this stage contains suspended solids and has to be $\mathrm{pH}$ treated and purified from $\mathrm{Na}_{2} \mathrm{SO}_{4}$ before it is released into the sea. In the dry stage (the most energy-intensive step), often a lot of water has to be evaporated; it can reach up to 6 tonnes of water for each one tonne of silica gel [16]. For this big amount of water, the dryer used must be very powerful and efficient. Though dependent on the type of silica gel desired by the manufacturers, the dryers used for silica gels need a high-temperature inlet and produce a significant amount of $\mathrm{CO}_{2}$ emissions and dust. Finally, machines do the packaging where the final product is then put in plastic/paper bags (size: $5-25 \mathrm{~kg}$ ). Needless to say, these machines also produce waste of dust and emissions to the air.

The following statistics were adapted from a European Commission Report, 2007 [16]. One tonne of silica requires 0.66 tonnes of $\mathrm{H}_{2} \mathrm{SO}_{4}, 3.90$ tonnes of water glass (as a source aqueous alkali metal solution) and $40 \mathrm{~m}^{3}$ of water. About 15-24 GJ is consumed for the same amount of silica [16]. The NREU (non-renewable energy use) for silica gel is $66.0-77.3(\mathrm{MJ} / \mathrm{kg}$ ), and the GWP100 (global 
warming potential in 100 years) is estimated to be between $3.48-4.12\left(\mathrm{~kg} \mathrm{CO}_{2}-\mathrm{eq} / \mathrm{kg}\right)$ [17]. Other than the energy required for production, treating the waste that comes out at various stages of production can be energy-demanding as well. The solid waste generated is about $29 \mathrm{~kg}$ for each tonne of silica on average, which is significantly lower than the waste generated for fumed silica. The treated wastewater generated for one tonne of silica is about $35 \mathrm{~m}^{3}$ on average. As for the emissions, and according to the European Commission Report 2007 [16], they can be classified into air and water emissions. The drying stage generates a large amount of dust; this is, of course, dependent on the drying technique used. On average, for one tonne of silica $1.3 \mathrm{~kg}$ of particles are emitted. In addition, if the drying process is generated by natural gas, the emissions of $\mathrm{CO}$ and $\mathrm{NO}_{x}$ are estimated to be 0.825 and $0.723 \mathrm{~kg}$ respectively on average for each tonne of silica. As for water soluble emissions, they consist mainly of $\mathrm{Na}_{2} \mathrm{SO}_{4}(588 \mathrm{~kg} / \mathrm{t}$ silica), but also of other particles. These particles are disposed of in the seas/rivers (6.6 kg particles/t silica excluding $\mathrm{Na}_{2} \mathrm{SO}_{4}$ ).

To recycle used silica gel in $120 \mathrm{~g}$ batches, we used a Carbolite electrical oven ELF 11-6 that consumes $1 \mathrm{~kW}$ per hour, making for the overall consumption of energy about $60 \mathrm{MJ} / \mathrm{kg}$ of silica gel. Comparing with buying new silica gel, we were able to cut down on energy by $10 \%$ and although this is not much, recycling larger amounts of silica gel can be of apparent value cutting down on energy, further. Then again, the process we use for recycling silica gel eliminates solid wastes and the use of water almost completely. In addition, during the recycling process, the silica is not physically moved from the laboratory where it is used. This facilitates logistics and circumvents the energy needs and pollution associated with the transport of the material.

\section{Conclusions}

Silica gel is used in our laboratories for the separation by adsorption chromatography of organic mixtures obtained from the synthesis of organic materials. We use about $22 \mathrm{~kg}$ of silica gel every year for our processes. In previous times, we have not treated silica gel wastes but asked that they are taken away as solid chemical waste. In the last 2 years, we have started to recycle silica gel waste by the simple process described above. As often we are separating organic compounds from triphenylphosphine oxide, it is expected that some amounts of phosphoric and polyphosphoric acids remain on the silica gel, and this has been supported by ICP-OES and EDS measurements of the recycled silica gel. Thus far, this has not decreased the quality of the silica gel as chromatographic material. However, that some structural changes of the silica gel do occur can be seen in the decreasing pore diameter $(4 \mathrm{~V} / \mathrm{A})$ and potentially in a decrease of water uptake with the number of recycling cycles, so that most likely the silica gel cannot be recycled indefinitely. Up until now, 37.5 $\mathrm{kg}$ silica gel from $50.7 \mathrm{~kg}$ silica wastes has been recycled from our laboratory that would otherwise have been declared as solid chemical waste. This saved the group 1265 Euro [(list price in Europe) = 5350 AED] in not buying new product ( $37.5 \mathrm{~kg}$ of pure silica gel). The waste disposal ( $51.3 \mathrm{~kg}$ of pure silica gel) would have cost 9400 AED. Therefore, apart from minimizing waste streams, 14,750 AED were saved by the procedure. As a final conclusion, it may be said that starting materials for research purposes that are relatively easily separated from their side products can be purified using recycled silica gel. In addition, recycled silica gel can be used in educational laboratories to contain wastes and costs.

Author Contributions: T.T. and F.S.W. have conceived this project and have carried out the actual thermal recycling. T.T. and A.A.-H. investigated the chromatographic separation of reaction mixtures on the recycled silica gel. M.D.A. and M.A. studied the environmental impact of the process. M.B. and A.A.-H. carried out the spectroscopic analysis of the products separated by column chromatography on the recycled silica gel. T.R. and F.H. carried out the SEM and EDS studies on the commercial and recycled silica gel.

Funding: This research received no external funding.

Acknowledgments: The authors thank Felix Guiabar Tripoli Labata for ICP-OES measurements and Bassam al Hindawi for the BET measurements.

Conflicts of Interest: The authors declare no conflict of interest. 


\section{References}

1. Loureiro, A.P.; de Souza, J.A.; Aparecido. D.; Fenrandes, J.B. Recuperação de silica gel: Nova alternative. Química Nova 1991, 14, 112-112.

2. Andreão, P.S.S.; Giacomini, R.A.; Stumbo, A.M.; Waldman, W.R.; Braz-Filho, R.; Ligiéro, C.B.P.; Miranda, P.C.M.L. Utilização e recuperação de sílica gel impregnada com nitrato de prata. Química Nova 2010, 33, 212-215.

3. Da Silva Riehl, A.B.; Da Cunha Pinto, A. Sílica gel: Uma alternativa. Química Nova 1988, 11, 329-330.

4. Teixeira, S.C.G.; Mathias, L.; Canela, M.C. Recuperação de silica-gel utilizando processos oxidativos avançados: Uma alternative simples de baixo custo. Química Nova 2003, 26, 931-933.

5. Neves, G.M.; Lenza, R.F.S.; Vasconcelos, W.L. Evaluation of influence of microwaves in the structure of silica gels. Mater. Res. 2002, 5, 447-451.

6. Christy, A.A.; Egeberg, P.K. Quantitative determination of surface silanol groups in silica gel by deuterium exchange combined with infrared spectroscopy and chemometrics. Analyst 2005, 130, 738-744.

7. Christy, A.A. Near infrared spectroscopic characterization of surface hydroxyl groups on hydrothermally treated silica gel. Int. J. Chem. Environ. Eng. 2011, 2, 27-32.

8. Moribe, K.; Masaki, M.; Kinoshita, R.; Zhang, J.; Limwikrant, W.; Higasdhi, K.; Tozuka, Y.; Oguchi, T.; Yamamoto, K. Guest molecular size-dependent inclusion complexation of parabens with cholic acid by cogrinding. Int. J. Pharm. 2011, 420, 191-197.

9. Yang, X.-F.; Li, Q.-L.; Chen, Z.-P.; Jin, H.-X.; Liu, B. Thermolysis parameter and kinetic research in copolyamide 66 containing triarylphosphine oxide. High Perform. Polym. 2018, 25, 502-507.

10. Yang, X.-F.; Li, Q.-L.; Chen, Z.-P.; Zhang, L.; Zhou, Y. Mechanism studies of thermolysis process in copolyamide 66 containing triarylphosphine oxide. J. Therm. Anal. Calorim. 2013, 112, 567-571.

11. Takamura, T.; Yoshida, H.; Inazuka, K. Infrared characteristic bands of highly dispersed silica. Langmuir 1987, 3, 960-967.

12. Zhdanov, S.; Kosheleva, L.S.; Titova, T.I. IR study of hydroxylated silica. Langmuir 1987, 3, 960-967.

13. Riegel, B.; Hartmann, I.; Kiefer, W.; Groß, J.; Fricke, J. Raman spectroscopy on silica aerogels. J. Non-Cryst. Solids 1997, 211, 294-298.

14. Warring, S.L.; Beattie, D.A.; McQuillan, A.J. Surficial siloxane-tosilanol interconversion during roomtemperature hydration/dehydration of amorphous silica films observed by ATR-IR and TIR-Raman spectroscopy. Langmuir 2016, 32, 1568-1576.

15. Al-Azani, M.; al-Sulaibi, M.; Al Soom, N.; Al Jasem, Y.; Bugenhagen, B.; Al Hindawi, B.; Thiemann, T. The use of $\mathrm{BrCCl}_{3}-\mathrm{PPh}_{3}$ in Appel type transformations to esters, O-acyloximes, amides, and acid anhydrides, $\mathrm{C}$. R. Chim. 2016, 19, 921-932.

16. European Commission. Integrated Pollution Prevention and Control. In Reference Document on Best Available Techniques for the Manufacture of large Volume Inorganic Chemicals -Solids and Others; Bref 0907; 2007.

17. Roes, A.L.; Tabak, L.B.; Shen, L.; Nieuwlaar, E.; Patel, M.K. Influence of using nanoobjects as filler on functionality-based energy use of nanocomposites. J. Nanopart. Res. 2010, 12, 2011-2028.

(C) 2018 by the authors. Licensee MDPI, Basel, Switzerland. This article is an open access article distributed under the terms and conditions of the Creative Commons Attribution (CC BY) license (http://creativecommons.org/licenses/by/4.0/). 